\title{
ESPIRITUALIDADE E FILOSOFIA: A EXPERIÊNCIA DA SIMPATIA UNIVERSAL EM MEIO AO OCEANOMUNDO
}

\author{
[SPIRITUALITY AND PHILOSOPHY: THE EXPERIENCE OF GENERAL SYMPATHY IN THE MIDDLE \\ OF THE OCEANWORLD]
}

Thiago André Moura de Aquino* Universidade Federal de Pernambuco, Brasil

\begin{abstract}
RESUMO: Neste artigo me proponho a elaborar uma resposta possível à questão acerca da relação entre filosofia e espiritualidade. $\mathrm{Na}$ primeira parte, pretendo delimitar o significado do termo "espírito", tal como será empregado no aprofundamento da discussão, partindo de referências histórico-conceituais da cultura ocidental. $\mathrm{Na}$ segunda parte, tematizo a espiritualidade in concreto, considerando diretamente a perspectiva imanentista de assumir e experimentar a relação existencial com o sagrado. Por último, proponho, em diálogo com Max Scheler, um esboço de análise e descrição de um modo do sentimento da simpatia, a unificação afetiva [Einsfühlung]. Irei designar este sentimento de simpatia universal, justamente por possibilitar um modo de abertura da existência ao cosmos, na qual a participação e integração do singular no todo são vivenciadas positivamente. Nesta experiência de imersão reconheço um solo comum que conecta a interrogação filosófica e espiritualidade naturalista.
\end{abstract}

Palavras-chave: Espiritualidade; simpatia; fenomenologia; Espinosa; Scheler
ABSTRACT: In this article I propose to elaborate a possible answer to the question about the relationship between philosophy and spirituality. In the first part, I intend to delimit the meaning of the term "spirit", as it will be used in the deepening of the discussion, starting from historical-conceptual references of Western culture. In the second part, I will focus on spirituality in concrete, directly considering the immanentist perspective of assuming and experiencing the existential relationship with the sacred. Finally, in dialogue with Max Scheler, I propose an outline of analysis and description of a form of sympathy, the affective union [Einsfühlung]. I will designate this feeling of universal sympathy, precisely because it allows a way of opening existence to the cosmos, in which the participation and integration of the singular in the whole are positively experienced. In this experience of immersion I recognize a common ground that connects philosophical questioning and natural spirituality.

KEYWORDS: Spirituality; Sympathy; Phenomenology; Spinoza; Scheler

* Professor no Departamento de Filosofia da Universidade Federal de Pernambuco, UFPE. Este texto é fruto da apresentação que fiz no IV. Colóquio Internacional de Estética e Existência: "Filosofia e Espiritualidade", realizado na UFPB em 2019. Agradeço aos organizadores do evento, os Prof.s Dr.s Iraquitan Caminha e Gilfranco Lucena, e a todos os participantes. Agradeço também a Marcos Batista, Miguel Bittencourt e Lucas Amorim pelos comentários sobre a primeira versão deste artigo.E-mail: tama_aquino@hotmail.com 


\title{
DA ESPIRITUALIDADE: O "SOPRO" DA VIDA E A MOBILIDADE EXISTENCIAL
}

\author{
"Como nossa alma, que é ar, nos governa e sustém, assim também \\ o sopro e o ar abraçam todo o cosmos."
}

A pesar da sua longa e venerável história, não é possível afirmar que o A conceito de "espírito" pertença ao vocabulário mais frequente do pensamento contemporâneo. Muito pelo contrário. Como observa Pierre Hadot no prefácio da obra Exercícios Espirituais e Filosofia Antiga: "não é mais de muito bom tom, hoje, empregar a palavra 'espiritual"' (HADOT, 2014, p. 20) Na atmosfera pósmetafísica que caracteriza a contemporaneidade filosófica, este conceito se tornou dissonante, fora de lugar. Este fato, entretanto, não nos obriga a tomar apressadamente o elemento divergente como sinônimo de inapropriação. A tensão presente na correlação entre a palavra "espírito" e a ambiência filosófica atual, pode ser encarada como uma boa ocasião para reconsiderar simultaneamente o pensamento filosófico e a condição humana. $\mathrm{O}$ enfrentamento desta tarefa pressupõe inevitavelmente a clarificação do significado da palavra em questão. Evidente que não pretendo apresentar, nesta seção, uma definição da essência da espiritualidade, mas tão somente destacar aspectos envolvidos no uso da palavra que sejam relevantes para avançar na direção da compreensão filosófica dos fenômenos existenciais implicados no entrelaçamento existência/mundo/divindade.

Em consonância com a tese hermenêutica de que há uma sabedoria incrustada na própria linguagem, parto do recurso às indicações provenientes da história da palavra em discussão. É de conhecimento geral que em algumas línguas ocidentais, o nome "espírito" contém uma referência experiencial à concretude do ato da respiração. Permanecendo no contexto do ocidente, podemos constatar tal referência na tradição greco-latina, por exemplo, através dos termos pneûma, que provém de pnéô, e spiritus que provém de spiro; bem como também na tradição bíblica através da palavra hebraica ruah. (VAZ, 2011, p. 206) Esta referência ao ato de respiração nos permite extrair da história da palavra, dois aspectos fundamentais para elaboração de um conceito preliminar de espírito: primeiramente, que espiritualidade necessariamente remete à vida ao destacar o sopro vital; em segundo lugar, que espiritualidade enquanto vitalidade implica mobilidade, trânsito, pulsação. Em síntese, extraio daí, que espírito pode ser compreendido como sinônimo de vida em movimento.

O primeiro aspecto é de caráter antropológico, capitulando o conceito de espírito entre as determinações fundamentais da vida humana. Ao exprimir o sopro vital, o espírito nomeia a vida que nos é peculiar, biós mais do que zoé; ou seja, o existir que acontece nas estruturas da compreensão e do sentimento e no exercício da liberdade na ação. Ao utilizar o termo "antropológico", refiro-me aqui não tanto a conceituação discursiva da antropologia filosófica, mas primariamente ao que lhe antecede, à vitalidade da vida em si mesma na concretude do seu acontecer temporal. Está claro que a expressão conceitual traz à palavra, no contexto da antropologia filosófica, o que já se dá primordialmente no existir. De fato, parte central da motivação para a reutilização em curso da palavra "espírito", emerge da sua possível capacidade de expressar o acontecer da existência, a experimentação que o ânimo faz de si no mundo atravessando transformações na pulsação cíclica da inspiração/expiração. Isto é convergente com a observação de Foucault, no curso Hermenêutica do Sujeito, de que atravessam a espiritualidade duas problemáticas existenciais essenciais: "(...) 0 problema a respeito do que se passa com o ser do sujeito (do que deve ser o ser do sujeito para que ele tenha acesso à verdade) e a consequente questão acerca do que pode ser transformado no sujeito pelo fato de ter acesso à verdade(...)." (FOUCAULT, 2010, p. 28) Espiritualidade é, sobretudo, convocação à experiência, mas não toda e qualquer experiência, mas a experimentação que conjuga verdade e existência transformando 
esta última. ${ }^{2} \mathrm{O}$ segundo aspecto, é, numa caracterização inicial, de caráter metafísico. Acompanhando a referência à respiração, à vida, podemos buscar identificar no conteúdo das experiências da vida espiritual sua orientação fundamental. Mais especificamente, podemos nos perguntar pela sua direção: para aonde sopra o espírito humano? No nosso contexto histórico-cultural atual, responde-se, mais usualmente, que o espírito sopra verticalmente. Elevando-se rumo à transcendência, sobe, ascende, operando uma ultrapassagem que se inicia no recolhimento do eu. É dentro si, no mais íntimo da interioridade, que se presume que aconteça a passagem para o plano da divindade transcendente. Considero relevante destacar nesta resposta mais recorrente dois pontos que são nitidamente separáveis. O primeiro ponto, mais definidor e central, de que espiritualidade é empregada frequentemente para nomear a relação com o sagrado, afirmando que a referência ao divino é constitutiva da existência humana. Pode-se ponderar, entretanto, comentando o segundo ponto, que o nosso vínculo constitutivo com o sagrado não se apresenta unicamente como movimento vertical na direção das alturas da transcendência; sendo também passível de ser experienciado, numa orientação alternativa, enquanto circulação unitária entre a terra e o céu, num movimento horizontal cujo acontecer integra a existência e o jogo do mundo.

Se tomarmos como parâmetro a caracterização, proposta por Richard Rorty, da metafísica enquanto a "descrição de como o céu e a terra são correlacionados" (RORTY, 1979, p.132), podemos diferenciar duas possibilidades de articulação entre tais "elementos". Na perspectiva da transcendência, afirma-se a descontinuidade entre céu e terra, constituindo-se a espiritualidade no movimento de ascendência, de elevação do terrenal rumo ao celestial. Os exercícios espirituais, nesse caso, são procedimentos para a religação com o transcendente através do recolhimento em si, numa transição da intimidade (interioridade) para a transcendência (altura). O voltar-se para dentro é, em geral, necessário enquanto reserva frente ao que é mundano e terreno (1 Jo 2,15). Na perspectiva da imanência, afirma-se a continuidade entre céu e terra, constituindo-se a espiritualidade no movimento do transitar, fluir, circundar o arco da existência em meio ao universo. Os exercícios espirituais são, aqui, caminhos de intensificação/renovação do sentimento de imersão no todo (abertura e habitação) e de celebração do vínculo com o acontecer da imanência (jogo do mundo).

Concluindo este exame provisório e sucinto da sabedoria histórico-experiencial da palavra "espírito", podemos retornar à colocação de Pierre Hadot. Segundo o autor, o uso do conceito de espírito para qualificar os exercícios, que são tema do seu estudo, se justifica por dois motivos principais: por indicar que nos exercícios espirituais é "todo o psiquismo do indivíduo" que está engajado e, também, por revelar que neles, o indivíduo "recoloca-se na perspectiva do Todo." (HADOT, 2014, p. 20) Em suma, a palavra "espírito" envolve três interrogações fundamentais. A pergunta antropológica pela natureza humana (quem sou eu?), a pergunta ontológica pela relação com o originário/divindade (qual a relação entre a existência e o primordial?) e a pergunta cosmológica acerca do mundo (qual o lugar do existente na totalidade?). Existência, divindade, mundanidade: nos tornamos capazes de ouvir essas ressonâncias na palavra "espírito" e através dela alcançamos uma atmosfera de interrogação investigativa que será desenvolvida na sequência deste texto.

\section{O PrincíPIO da ImanênCia: O TOdo-UnO E A DIVINdAde do MUNDO}

\section{"A fonte desagua na própria fonte"}

\section{Orides Fontela ${ }^{3}$}

A diferenciação entre dois tipos de experiência existencial com a divindade e suas respectivas traduções histórico-conceituais, delineada anteriormente, revela que a natureza desempenha no âmbito da religião o papel de parâmetro diferenciador. Em termos mais amplos, está claro que este papel ultrapassa os limites do domínio 
religioso; pois é concretamente evidente que originalmente toda invenção humana surge, implícita e explicitamente, da experiência do mundo. Que o mundo exista e seja tal como é (ininterrupta mutação e jogo), desperta em nós, seres humanos, fascinação e maravilhamento. É o aparecer contínuo e exuberante da totalidade cósmica que ocasiona a criação na arte, a interrogação pela origem na filosofia, bem como também o sentimento de reverência ao sagrado na religião. Arte, filosofia, religião são os modos originais de correspondência à presença do cosmos, através das quais expressamos a verdade do existir. No que diz respeito à religião, podemos constatar que a natureza serve como parâmetro para demarcação das formas de significação da experiência com o sagrado, o que podemos verificar historicamente através da mencionada bifurcação entre a pressuposição de que a potência infinitiva (divindade, Deus) extrapola o mundo na perspectiva transcendente (Is 45,15 ) e a afirmação alternativa de que habita no coração do mundo na perspectiva imanentista. Na obra Essência e Formas da Simpatia, Max Scheler exemplifica expressões históricas desta distinção destacando "a mística cristã, acósmica e espiritual, do amor" (SCHELER, 1973, p. 95) como pólo oposto à unificação afetiva [Einsfühlung], greco-antiga ou oriental, com o cosmo. ${ }^{4}$

A experiência do sagrado na imanência do mundo admite diferentes caracterizações. Ela pode ser designada como sendo um tipo de religião ecológica, ou seja, uma religião que "põe a relação do ser humano com o todo-natural [Gesamtnatur] e com o cosmos no centro do seu interesse plenamente piedoso, que se reconecta com 'a grande casa do universo"'. (MYNAREK, 1986, p. 14.) Tal experiência também pode ser descrita como implicando um eixo de perspectiva cosmo-existencial pelo reconhecimento do paradoxo unitário na relação entre a existência/cosmos, assumindo que "cada indivíduo é uma expressão genuína da Natureza, narrada à luz de uma cultura: compreensão original, configurando o estado natural, ou estado-de-ser, relação basilar, locus definitório, terminante, da existencialidade" (BARBIER, 2009, p.11-12.) Outra possibilidade seria articular a partir desta vivência um naturalismo espiritual, assumindo que "o espírito é uma força natural" (STEINHART, 2019, p. 312.) Sem exclusão de tais formulações (religião ecológica, perspectiva cosmo-existencial, naturalismo espiritual), sabe-se, que há uma caracterização que as antecede em antiguidade e as abrange pela amplitude de sua presença histórico-cultural, refiro-me ao termo "panteísmo". Ele foi proposto pela primeira vez no texto Socianism truly stated by a Pantheist (1705), escrito pelo pensador irlandês John Toland ${ }^{5}$. Mas foi tão somente em 1720, com a publicação do opúsculo Pantheisticon: or the form of celebrating the Socratic-society, que o autor, de fato, apresentou uma exposição mais articulada da teologia que conjuga em unidade o divino (theós) e a totalidade (pan). O texto contém, além da exposição do panteísmo, uma série de considerações descritivas e instruções práticas acerca das, assim chamadas, "sociedades socráticas", associações formadas por filósofos e pessoas instruídas (learned) que foram fundadas, desde a antiguidade, com intuito de promover encontros para celebração da sabedoria e de uma vida eticamente virtuosa numa atmosfera de amizade e meditação. Um dos propósitos do autor com a publicação do texto, é justamente de promover a refundação de agrupamentos desse tipo a partir da inspiração proveniente da antiguidade greco-romana. ${ }^{6}$ Segundo Toland, os participantes de tais sociedades são "chamados, na sua maioria, panteístas, em função de um parecer [Account] acerca de DEUS e do UNIVERSO, que é peculiar a eles." (TOLAND, 1751, p.14) São chamados assim, explica o autor irlandês, porque de acordo com eles "a força e energia do todo [Whole]" (TOLAND, 1751, p.17), Deus, a divindade, "não ser separada do universo ele mesmo, a não ser por uma distinção de razão [Distinction of Reason] apenas." (TOLAND, 1751, p.18). Nesta enunciação inaugural, o panteísmo se define pela compreensão/sentimento da divindade integrada ao universo, dispensando qualquer separação na direção da transcendência. Esta proposta de Toland pertence ao período moderno marcado pela filosofia das luzes, pela crítica à tradição, ao medievo comprometido com o extramundano. Nesse contexto, sabemos que o pensamento do bendito holandês Bento de Espinosa foi decisivo na recuperação e reformulação da doutrina do Todo-uno, na medida em que apresenta uma 
versão radical de iluminismo. Apesar do termo "panteísmo" ter surgido posteriormente à publicação da obra de Espinosa, dali em diante, em especial a partir da "segunda metade do século XVIII, panteísmo e espinosismo foram utilizados como sinônimos" (HORNÄK, 2010, p. 269). De fato, a afirmação panteísta do entrelaçamento entre o divino (theós) e o todo (pan) se aproxima bastante do conhecido dístico espinosano: Deus sive natura. ${ }^{7}$

De que modo esta identificação entre Deus e Natureza é estabelecida? Fundamentalmente, através de uma mudança na compreensão da noção de causa eficiente. Usualmente, se concebe que na relação causa/efeito ocorre uma "passagem" na causação. No término da ação causal, o efeito (produto) adquire autonomia frente à causa, quer dizer, se estabelece a exterioridade do resultado frente à ação de produção. Espinosa designa este tipo de relação de causalidade transitiva. Na causa transiens, o efeito é posto, enquanto resultado da produção, fora da ação causal, subsistindo à parte. Por exemplo, um artefato qualquer, digamos um instrumento musical, depois do término da produção, permanece sendo em separado do artesão. É esta causalidade pressuposta na ideia de creatio, pois o mundo subsiste, enquanto criatura, separado de Deus depois do ato da criação. Na Ética (1677), Espinosa afirma que há um outro sentido de causalidade, que denomina de causa immanens: "Deus é causa imanente, e não transitiva, de todas as coisas." (E I P 18). Na causação imanente, a causa permanece no efeito e o efeito na causa, sem separação ou distância, pois a causa opera sua eficiência de produção em si mesma. O núcleo do pensamento filosófico de Espinosa, que reside na tese da unicidade da substância, é desenvolvido através da aplicação teórica consequente do "princípio da imanência" (HORNÄK, 2010, p. 12) na elaboração de uma ontologia integral da natureza.

Não será possível, nem é a pretensão deste artigo, acompanhar o caminho axiomático-dedutivo da obra em suas proposições, demonstrações e corolários. Ao invés disso, comento brevemente a distinção ontológica basilar sobre a qual assenta toda a complexa e elegante arquitetônica da Ética, refiro-me à distinção entre substância e modo finito: "Tudo o que existe, existe ou em si mesmo ou em outra coisa." (E I Ax.1) Substância é definida, na primeira parte intitulada De Deo, como "aquilo que existe em si mesmo e que por si mesmo é concebido, isto é, aquilo cujo conceito não exige o conceito de outra coisa do qual deva ser formado." (E I def. 3) A substância não é compreendida aqui como substrato de propriedades, é determinada principalmente pela autossuficiência. Esta marca da independência denota, em seus aspectos ontológico (existir por si) e lógico (concebida por si), o caráter absoluto, a capacidade de autofundamentação da natureza. Em sua essência, a substância é uma potência infinita, "uma afirmação absoluta da existência de uma natureza" (E I P 8 esc. 1), causa sui. Ela se autoproduz no mesmo sentido em que produz todas as coisas enquanto modificações finitas dos seus atributos infinitos (extensão e pensamento). As "coisas particulares" (corpos e ideias) são as "afecções dos atributos de Deus, ou seja, modos pelos quais os atributos de Deus exprimem-se de uma maneira definida e determinada" (E I P 25 cor). Os modos finitos são definidos, em contraste com a autossuficiência da substância, como "aquilo que existe em outra coisa, por meio da qual é também concebido" (E I def. 5) e, portanto, envolvendo dependência lógica e ontológica. Isto vale também para cada indivíduo humano, cuja essência, corpo e mente em unidade psicofísica, é "constituída por modificações definidas dos atributos de Deus” (E II P 10 Cor.) Nesta visão unitária da natureza, a aplicação do princípio da imanência possibilita captar a causação dos modos finitos como a produção de efeitos imanentes à substância infinita. É uma só e única natureza que pode ser apreendida, ora como o que se expressa em ação naturante, ora como expressa, naturada, nos seus produtos imanentes. Estes são os dois momentos principais da natureza, por natura naturans, "devemos compreender o que existe em si mesmo e por si mesmo é concebido, ou seja, aqueles atributos da substância que exprimem uma essência eterna e infinita, isto é, (...) Deus enquanto é considerado como causa livre." E por natura naturata, "tudo o que se segue da necessidade da natureza de Deus, ou seja, de cada um 
dos atributos de Deus, enquanto considerados como coisas que existem em Deus, e que, sem Deus, não podem existir nem ser concebidas." (E I P 29 esc.) Através desta unidade entre natureza naturante e natureza naturada, a palavra "natureza" readquire no pensamento espinosano o significado de totalidade.

Considerando a concepção da relação entre modo finito e substância infinita

78 descrita na Ética, Max Scheler observa que a doutrina de Espinosa é "designada com justeza panteísmo." (SCHELER, 1959b, p. 51). Para este tipo de visão de mundo, completa o fenomenólogo alemão, é essencial "o pensamento de que Deus e o mundo se relacionam não como causa e efeito, como criador e criatura, mas que seriam idênticos em sua substância." (SCHELER, 1959b, p. 52). É verdadeiro, todavia, que a interpretação panteísta do pensamento de Espinosa não é ponto pacífico na recepção da obra. Tomada em si mesma, esta é uma questão hermenêutica desprovida de maior importância. Ainda assim, a discussão deste ponto talvez seja relevante pela oportunidade que abre para o aprofundamento de um aspecto frequentemente incompreendido no conceito de panteísmo. No geral, a recusa da classificação de Espinosa como panteísta se fundamenta no argumento de que o panteísmo consistiria na fusão, para não dizer confusão, entre finito/infinito, o que não se verificaria na Ética (cf. E II P 10 esc.). Não é, inclusive, incomum nos depararmos com a afirmação de que o panteísmo seja vago, isto ocorre muitas vezes em textos repletos de observações próximas do reconhecimento da unidade. Em tais contextos surge de repente, talvez como decorrência do que Deleuze denominou de "vertigem da imanência", formulações do tipo: "bem, mas isso seria assumir um panteísmo difuso". De onde provém a necessidade da advertência? Voltando a Espinosa, cito o comentário de Hornäk de que não há na Ética "uma concepção panteísta, no sentido de coincidirem a natureza da substância e a natureza dos modos. A proposição 15 não diz que 'tudo o que existe é Deus', e sim, 'Tudo o que existe, existe em Deus'. Se fosse o caso, poder-se-ia talvez falar de um panenteísmo, uma vez que os modos não são idênticos a Deus, mas o são em Deus." (HORNÄK, 2010, p. 78) É É, todavia, incorreta a enunciação do panteísmo por meio da tese: "tudo o que existe é Deus". De onde provém o equívoco? De um lado, provém da despreocupação ou desinteresse em recuperar a origem do conceito, pois, no mais das vezes, um uso genérico da palavra "panteísmo" é assumido como satisfatório para a finalidade dos mais variados estudos em filosofia, história, teoria da literatura et cetera; de outro lado, provém da ambiguidade de um termo grego utilizado no conceito. Existem, pelo menos, duas opções em grego para nomear a totalidade, as palavras tó holon e tó pan. ${ }^{9}$ Esta última opção, é frequentemente compreendida como sinônimo de somatório, como designação de um todo que seria um mero conjunto formado pela reunião posterior de uma multiplicidade, ou seja, como um simples agregado. Deste modo, o termo "panteísmo" aparenta identificar o divino (theós) com todas as coisas no plural, com tudo e cada uma das coisas. Se consultamos o texto que apresenta pela primeira vez e define o termo, o já citado opúsculo Pantheisticon de John Toland, não é, porém, este o sentido de emprego da palavra grega tó pan. Na segunda parte da obra, que contém uma proposta de liturgia para os encontros panteístas, Toland apresenta as seguintes frases para recitação no início dos encontros de celebração da sociedade socrática: "All things in the World are one, and one is All in all Things (...) What's All in all Things is God (...)". (TOLAND, 1751, p.70)

A compreensão do significado da passagem acima citada, depende da identificação correta do insight filosófico fundamental que expressa. Trata-se do que os alemães denominam de doutrina do Todo-uno ${ }^{10}$, um pensamento com desenvolvimentos e aprofundamentos em diversos períodos históricos nas tradições culturais do ocidente e oriente. No ocidente, compõe o cerne do pensamento pré-socrático já desde o primeiro pensador como observa Aécio, sugerindo uma síntese: "Tales e sua escola: O cosmos é um"11 [héna tón kósmos]. Seguindo essa pista pré-socrática, somos remetidos, quase que inevitavelmente, na leitura das frases, acima citadas, de Toland ao fragmento $10 \mathrm{de}$ Heráclito: “(...) de todas as coisas um, um de todas as coisas." [ek pánton hèn kai eks henòs pánta] (HERÁCLITO, 2012, p.133). A doutrina do Todo-uno diz respeito 
justamente ao problema da relação entre multiplicidade e unidade; almeja explicitar filosoficamente os relata entrelaçados, uno e múltiplo, bem como também a relação na qual a pluralidade se articula numa unidade. ${ }^{12}$ É perfeitamente plausível defender a partir destas aproximações, que palavra grega tó pan nomeia no conceito de panteísmo um tipo de totalidade cuja unidade unifica "previamente" seus momentos numa articulação originária. Outra vez sugerindo uma aproximação possível com Heráclito; pode-se afirmar, em outras palavras, que a divinização do mundo, proposta pelo panteísmo, não é a divinização de mero agregado plural (todas as coisas/tudo), mas do Todo-uno, do Hèn-Pánta (Fr.50). Na perspectiva imanentista, o divino (theós) é o um, único, uno, o que reúne a totalidade do ente (pánta tá ontá). Na definição de MacIntyre, o panteísmo é visão de que "tudo o que existe forma uma 'unidade' e que esta unidade omni-inclusiva [all-inclusive] é, em algum sentido, divina." (MACINTYRE 1967 apud LEVINE, 1994, p.1)

Assim sendo, é perfeitamente coerente interpretar Espinosa numa apropriação panteísta. É claro, entretanto, que importa menos a defesa do que parece ser uma mera classificação, do que a ênfase no princípio da imanência e o reconhecimento de que contém possibilidades de pensamento que ainda permitem aprofundamentos e desdobramentos. Imanência, é a sugestiva indicação conceitual de uma originação sem a formação de domínios separados ou planos contrapostos vertical e hierarquicamente. Etimologicamente, a palavra é formada pelo prefixo "in" que indica pertencimento/inserção e o verbo "manere" que significa permanecer, demorar-se. $\mathrm{Na}$ imanência, em ato de geração, o que decorre do originário permanece no mesmo plano de onde provém. Na causalidade transitiva, o trânsito significa saída, ultrapassagem, passagem de um domínio para um outro, logo, uma externalidade, um "fora". $\mathrm{Na}$ imanência, ao invés disso, há permanência e pertencimento. Giorgio Agamben propõe em seu texto Imanência absoluta, que a imanência envolve um movimento, de certo modo circular, pois o que emerge na imanência imerge nela. Se consideramos a originação recorrendo à metáfora do surgimento da água de uma fonte, o que jorra e surge ("manare") permanece ("manere") no mesmo plano da fonte. Em termos poéticos-imagéticos, seria possível falar em um retorno cíclico da água à própria fonte; pois este "jorrar não sai de si, deságua incessantemente e vertiginosamente em si mesmo." (AGAMBEN, 2000, p. 176) Há em Espinosa, pelo menos uma passagem (E I P 17 esc.) na qual o autor holandês chega a recorrer à imagética da fluência, empregando o verbo efluere para descrever as "infinitas coisas" que se seguem da suprema potência de Deus. O sequitur espinosano, todavia, não admite nenhuma conotação temporal, pois toda a decorrência da atividade da substância infinita se dá na eternidade, "onde não há quando, nem antes, nem depois". (E I P 33 esc. 2) Sabemos, todavia, que a aplicação do princípio da imanência não precisa excluir o devir, podemos conceber que a originação do que provém desta fonte é um "deslocamento da imanência em si mesma, a abertura a um outro que, porém, permanece absolutamente imanente. Isto é, aquele movimento que Deleuze, jogando com a emanação neoplatônica, chama de imanação." (AGAMBEN, 2000, p. 172).

Retorno à questão acerca da relação entre espiritualidade e filosofia. Com as sucintas considerações desta seção, pretendo ter tornado claro que existe um possível liame entre o pensamento filosófico do Todo-uno e a perspectiva panteísta da divinização do cosmos. A convergência é garantida pelo compromisso comum com o princípio da imanência, que permite uma visão unificada da totalidade enquanto tema de meditação filosófica ou correlato principal da reverência religiosa. Esta proximidade, desperta a pergunta pela estrutura da experiência da unidade do todo. O que pode se dizer acerca desta vivência de unidade? De que maneira se entrelaçam na experiência existência, mundo e divindade? Seria possível elaborar uma análise e descrição fenomenológica da consonância entre o existir singular e o acontecer do mundo? $\mathrm{Na}$ sequência tentarei apresentar uma interpretação filosófica da experiência da unidade através de uma breve análise e descrição fenomenológica do sentimento da simpatia. 


\section{A Simpatia universal EM Meio aO OCEANOMUNDO}

"Man come from Nature in order to see Nature in himself; that ist, Nature come to itself in order to see itself in Man"'13

"O homem, um microcosmos"14

Daisetz T.Susuki

Demócrito

A doutrina do Todo-uno é, sem dúvida, um pensamento extemporâneo à nossa época. São claras as resistências diante de qualquer tentativa de afirmar a visão da totalidade integral como imprescindível ao filosofar. $\mathrm{Na}$ religião, predomina culturalmente a perspectiva transcendente da tradição judaico-cristã que celebra um Deus que não pertence ao mundo (Jo 18,36). Na filosofia, a posição pós-metafísica acusa esta proposta de envolver o risco de promoção sub-reptícia de um ato totalitário de redução do outro ao mesmo e/ou de supressão da singularidade. Para não mencionar a suspeita de que seria necessário retomar o projeto de formação de um sistema total de saber, o que se presume ser ultrapassado. Na ciência, o trabalho de pesquisa opera aceitando o falibilismo das teorias e hipóteses, favorecendo a coleta dos fatos e dados, dispensando uma teoria de explicação global. Estas observações são incompletas e imprecisas, todavia, ao invés de tentar discutir a possível importância da noção de totalidade em cada um destes domínios, considero mais pertinente ir até a raiz da dificuldade. De onde provém a referência à totalidade que nos constitui? Não é, de fato, descabida a pretensão de apreensão intelectual do todo? De que modo seria possível tematizar discursivamente a totalidade? Encontramos um esboço de resposta na fenomenologia contemporânea, mais especificamente, em duas contribuições fundamentais e complementares que passo a considerar.

A primeira contribuição, é a (re)descoberta feita por Max Scheler, elaborando uma fenomenologia da vida emocional, de que os sentimentos, além serem tema privilegiado de investigação filosófica, são em si mesmos fontes de conhecimento filosófico na medida em que possibilitam experiências, cujo conteúdo revelado a filosofia pode aproveitar na sua meditações e análises. Não se trata meramente de buscar uma simples complementação de teorias ou visões de mundo com sugestões afetivas contingentes. Scheler observa, na obra O Formalismo na Ética e a Ética material dos valores, que o fundamental a se reconhecer, talvez superando preconceitos racionalistas, é de que "há um tipo de experiência, cujos objetos são completamente fechados ao intelecto." (SCHELER, 1916, p. 262) Nas emoções Scheler descobre “órgãos de apreensão de valores” (SCHELER, 1916, p. 262), ou seja, reconhece atos intencionais capazes de doação/entrega de fenômenos, que são inacessíveis por outras vias. Martin Heidegger reconhecerá, posteriormente, a importância desta (re)descoberta de Scheler da potência reveladora da disposição [Befindlichkeit], afirmando até mesmo que "as possibilidades de abertura do conhecimento são muito curtas diante do abrir originário das tonalidades de humor (...)". (HEIDEGGER, 2001, p. 134) No parágrafo 29 do tratado Ser e Tempo, encontramos uma análise fenomenológica da estrutura da disposição (estrutura ontológica do sentimento) em seus três traços essenciais: abertura da facticidade do eu, do todo do mundo e dos outros entes. O primeiro traço, indica que toda tonalidade de humor abre a facticidade do meu eu: o fato de que sou. Em todo sentir, há um sentir-se. O segundo, que em toda tonalidade de humor se abre também a totalidade do mundo; assim, o fato de que sou, que me é dado no humor, é desvelado enquanto um ser em meio à totalidade, na qual, terceiro traço, outros entes que encontro me tocam, afetam. Destaco como segunda contribuição da fenomenologia, a desvinculação do sentimento do princípio da subjetividade; ou seja, sua determinação enquanto um momento da abertura do humano. O sentimento não é uma ocorrência psíquica ou subjetiva, pertencente ao domínio da consciência, é um existencial, uma estrutura de ser da existência humana. Parece-me que combinadas, estas duas 
contribuições da pesquisa fenomenológica (a potência de revelação dos sentimentos e seu caráter de abertura da existência) podem abrir um caminho para a reconsideração da doutrina do Todo-uno. Aplicando à problemática da totalidade o procedimento padrão de toda investigação fenomenológica - estabelecimento claro do acesso aos fenômenos - questionamos: de que modo me é dado o tema em consideração: a totalidade? Se é verdadeiro "que nós nunca podemos apreender a totalidade do ente em si e absolutamente, é certo, porém, que nos encontramos postados em meio ao ente de algum modo desvelado em sua totalidade. No fim, há uma diferença essencial entre a apreensão da totalidade do ente em si e o encontrar-se em meio ao ente na totalidade. Aquela é fundamentalmente impossível. Este, acontece constantemente em nosso ser-aí. Parece, sem dúvida, que em nossa rotina cotidiana estamos presos sempre apenas a este ou àquele ente, como se estivéssemos perdidos neste ou naquele domínio do ente. Mas por mais fragmentado que possa parecer o cotidiano, ele sempre retém, mesmo que vagamente, o ente em uma unidade de "totalidade"'. (HEIDEGGER, 1996, p.110) Torna-se claro, então, que ao invés de serem ocorrências passageiras e secundárias, as disposições (tonalidades de humor) ou sentimentos possibilitam a experiência fundamental da existência: abrem o fato de que sou/existo em meio a totalidade (cosmos), em relação de encontro com os outros entes.

A partir das considerações anteriores, cabe inquirir se a filosofia, que medita acerca do Todo-uno e a espiritualidade panteísta, que diviniza o mundo, não estão, ambas, sustentadas por um sentimento fundamental capaz de abrir a existência humana em meio a totalidade no modo da integração participante. Proponho que a simpatia, ou pelo menos uma das suas formas básicas, preenche essa função desveladora de abrir a minha existência em meio a totalidade no "como" da integração/participação, ou seja, numa experiência de unidade que desabilita qualquer cisão entre meu eu e o cosmos. De fato, a etimologia da palavra "simpatia" já contém uma sugestão nesta direção de unificação, pois simpatia é sentimento [pathos] de unidade [syn]. Simpatizar é sentir-se um, é unir-se-com, é sentir união. Na obra Essência e Formas da Simpatia, Max Scheler apresenta, logo no início, o caráter multifacetado deste sentimento, ressaltando que sua investigação fenomenológica possui relevância para diversos campos do saber como a psicologia, a sociologia, a teoria do conhecimento e a metafísica. Irei me deter neste último campo, porém, antes de examinar a tentativa de interpretação metafísica da simpatia, será necessário tratar da distinção entre os conceitos de empatia [Nachfühlen], co-sentimento [Mitfühlen] e unificação afetiva [Einsfühlen].

Traduzo por empatia o termo alemão "Nachfühlen", pelo fato de que o conceito equivale ao que Husserl, Edith Stein e outros denominaram de "intropatia" [Einfühlung]. ${ }^{15}$ Trata-se do ato intencional de compreensão da vida alheia, a intencionalidade que originariamente me dá a existência do outro eu e suas vivências. A compreensão do outro é uma espécie de sentir [fühlen] posterior [nach], uma recuperação da vivência do outro em mim, portanto, um Nachfühlen. Este ato de doação do sentimento alheio fundamenta a possibilidade de um sentir-com [Mitfühlen], ou seja, que eu me volte para o estado emocional do outro compartilhando seus sentimentos. Para tanto, não é necessário que ocorra uma duplicação do sentimento do outro em mim. Por exemplo, posso sentir compaixão [Mitleid], modo do co-sentimento, pelo sofrimento do outro sem que eu mesmo esteja sofrendo ou seja tomado (contágio afetivo) pelo sofrimento alheio. É somente porque a empatia me dá acesso ao sentimento alheio, que posso intencionar, numa relação de compartilhamento, seu "estado emocional", somente por esta via posso sentir-com o outro seu sentimento.

Durante toda sua investigação fenomenológica da simpatia, é perceptível a preocupação de Scheler em marcar a diferença entre a empatia e o co-sentimento, de um lado, frente à unificação afetiva [Einsfühlen], de outro lado. Centrado na problemática da relação com outro, o pensador considerou importante destacar que na empatia e no co-sentimento não há identificação entre o meu si-mesmo e o do outro. Nos dois casos, a "distância fenomenal do eu" é resguardada, ao contrário do que acontece na unificação afetiva. Nos diversos momentos do livro, porém, nos quais a 
questão da relação com o outro-eu deixa de ser o foco de análise, o texto se torna, nas palavras de Paul Ricouer "de certo modo uma apologia da fusão afetiva. De modo complacente, ele vai encontrá-la no êxtase dos mistérios gregos, na alma primitiva e em todo primitivismo psíquico de ordem infantil ou de ordem patológica, nas emoções eróticas e no sentimento maternal, no instinto conforme o sentido de Driesch e de

82 Bergson." (RICOUER, 2009, p.316). Ao traduzir o termo "Einsfühlung" por fusão afetiva, Ricouer opta por assumir que na identificação que acontece na experiência deste sentimento, há suspensão completa da diferença entre os polos da relação. Considero, todavia, que a unificação afetiva admite variações de experiência que incluem fusão, como por exemplo o êxtase místico, porém também a união que resguarda a diferença, como por exemplo, na contemplação estética das formas naturais.

A unificação afetiva possibilita a experiência de integração, um sentir-se [fühlen] em união [eins] com o outro polo da relação. Nisto se revela que, existencialmente, a unidade não é um dado apreendido conceitualmente pelo entendimento, mas um evento de união afetiva, uma unificação. É justamente esta forma de simpatia, a unificação afetiva, que abre o fato de que sou parte/participante, existindo em meio ao acontecer do mundo (jogo cósmico), encontrando as coisas, relações e ocorrências num sentimento de repercussão conjunta. Nesta experiência, a conexão entre os termos da relação é de entrelaçamento, pois na unificação afetiva sinto-me em unidade com o cosmos e com o que encontro em meio ao cosmos; em toda ação e acontecimento repercute a totalidade. Esta integração existência/cosmos é poetizada, por exemplo, por Paulo Leminski no verso: "quando chove, eu chovo, faz sol, eu faço, de noite, anoiteço" É justamente esta experiência de integração, que me faz sentir-me um gesto no movimento do cosmos, o que justifica denominar este tipo de simpatia de simpatia universal ${ }^{16} \mathrm{Na}$ unificação afetiva eu experimento um senso de participação do todo na minha existência e da minha existência no todo.

A experiência fundamental de integração determinada através do conceito de imanência, descrita como cerne do sentimento simpático de unificação afetiva, também pode ser considerada através do recurso à imagem da imersão no "oceano do ser". A expressão passa a circular, pela primeira vez, no ocidente, através dos textos de Romain Roland. O escritor francês se deparou com esta expressão no relato de experiência mística feita pelo hindu ramakhrisna. ${ }^{17}$ Existem também ocorrências da imagem no budismo, por exemplo, conta-se que o mestre Zen Seppo teria dito certa vez aos monges num sermão, citado pelo estudioso budista Daisetz Susuki: "vocês são como aqueles que, enquanto imersos no oceano, estendem suas mãos clamando por água."18 A análise psicanalítica proposta por Freud, a pedido de Roland, nos ensaios $O$ Futuro de uma Ilusão e Mal-estar na Civilização, contribuiu para a divulgação e a notoriedade desta imagem. Saarinen, no artigo Análise conceitual do Sentimento Oceânico, distingue quatro momentos da integração da existência no todo através da unificação afetiva, que são recorrentes em diversos relatos e testemunhos literários: (i) unicidade ou união com o polo com qual me encontro em relação, (ii) expansão da existência, significando uma impossibilidade de separação, de um permanecer à parte; (iii) vínculo, ou seja, um sentimento nítido de comunhão e contato com o outro com quem me integro e me unifico e (iv) presença no agora, uma espécie de suspensão do tempo linear em prol de uma plenitude do instante. (SAARINEN, 2015, p.12-14) União com o todo, expansão do eu, vínculo existência/mundo, presença no instante: a unificação afetiva é um sentimento de simpatia universal que revela a existência imersa no "Oceanomundo" (PRADO JUNIOR 2000, p.315)

Retorno, então, à questão inicial: Qual é a relação entre filosofia e espiritualidade? Reconheço que a unificação afetiva, este sentimento fundamental de imersão participativa da existência no oceano do ser, opera como o elemento comum entre o exercício da interrogação filosófica e a celebração religiosa. A experiência da unificação afetiva, está na origem da busca filosófica de uma sophia tou kósmou, uma sabedoria do mundo. Um caminho de pensamento que se inicia nos pré-socráticos, 
reaparece entre os estóicos, em Giordano Bruno, Espinosa, Schelling e outros; e que também pode ser reinventado na circunstancialidade do pensamento contemporâneo. Noto que o sentimento da simpatia, no modo da unificação afetiva, reconhecida em sua potência de desvelamento e caráter mundano, abre a possibilidade de elaboração e aprofundamento de uma fenomenologia da natureza. Este projeto de pesquisa fenomenológica torna-se extremamente relevante diante da crise ecológica que mostra o limite da relação unicamente pautada pela ciência natural e pela técnica, exigindo formas alternativas de compreensão e sensibilidade para com o cosmos. Já encontramos nas obras de Max Scheler, Heidegger, Merleau-Ponty e Eugen Fink contribuições pertinentes para a investigação fenomenológica da natureza, cuja principal tarefa consiste em analisar e descrever as experiências concretas deste amplexo compreensivo-afetivo da existência humana com o universo, no qual a existência é abertura para a totalidade cósmica que a abrange, encontrando nela sua origem e morada. A experiência da unificação afetiva, está também na origem da reverência religiosa ao cosmos inspirando invenções artísticas e celebrações ritualísticas da sacralidade cósmica concretamente desenvolvida no taoísmo, zen-budismo, estoicismo, panteísmo. Uma prática religiosa de integração com os ciclos cósmicos (estações, fases da vida, nascimento/morte) e com as paisagens e lugares, e, sobretudo, de exercício da sensibilidade à presença do sagrado no cotidiano (como no dito zen: "corto a lenha, pego a água, é maravilhoso" ou mesmo como Heráclito junto ao fogo). Nos dois casos, filosofia e religião, é nítido o elemento comum do sentimento de participação e da atenção compreensiva ao acontecer da totalidade. A amizade pela sabedoria que medita o Todo-uno na filosofia e a reverência pelo sagrado que diviniza o mundo na religião são formas diferentes de desdobramento do mesmo amor, o amor pelo mundo. A espiritualidade, palavra que designa o acontecer da existência em meio ao mundo em vinculação com sagrado, tem sua concretização plena no sentimento do Todo-uno [AllEinheits-Gefühl] (SCHELER, 1973, p. 80), origem do despertar da interrogação filosófica e da reverência religiosa. Este sentimento é um índice existencial do entrelaçamento entre existência, mundo e divindade, nela se revela a possibilidade da integração sob a forma da consonância com o mundo. Vivendo em uníssono com o cosmos, simpatizando com o universo, a existência faz a afirmação da unidade: "Tudo o que está em acordo contigo está em acordo comigo, ó mundo" (Marco Aurélio, Meditações, IV, 23).

\section{REFERÊNCIAS}

AGAMBEN, Giorgio. A Imanência Absoluta, in: ALLIEZ, Éric. (Org.). Gilles Deleuze: uma vida filosófica. Coordenação de tradução de Ana Lúcia de Oliveria. São Paulo: Editora 34, 2000, p. 169-192.

ALLIEZ, Éric. (Org.). Gilles Deleuze: uma vida filosófica. Coordenação de tradução de Ana Lúcia de Oliveria. São Paulo: Editora 34, 2000.

AQUINO, Thiago. A Fenomenologia da distinção humana: Scheler e o projeto da antropologia filosófica, Síntese, Belo Horizonte, v.42, n.132, p. 61-80, 2015.

BARBIER, Régis. Panteísmo. A religiosidade do presente. Olinda - PE : Livro rápido, 2009.

BECKENKAMP, Joãosinho. A Penetração do Panteísmo na Filosofia Alemã. In: $O$ que nos faz pensar, n.19, dezembro 2005, p. 7-27.

BORNHEIM, Gerd A. Os filósofos pré-socráticos. São Paulo: Ed. Cultrix, s.d.

BORGES, Vitor S. Sentimento Oceânico: um estudo da experiência religiosa a partir de Freud e Romain Rolland. Dissertação de Mestrado - Universidade Católica de Brasília, 2008.

CRAMER, Konrad. Gedanken über Spinozas Lehre von der All-Einheit. In: HENRICH, Dieter (Org.). All-Einheit. Wege eines Gedankes in Ost und West. Stuttgart : Klett-Cotta, 1985, p.151-179.

CURLEY, Erdwin. How Spinozistic Was Toland's Pantheism?, In: DILLER, Jeanine; KASHER, Asa. (Org.) Models of God and Alternative Ultimate Realities. Heidelberg: Springer, 
2013. p.643-653.

DELEUZE, Gilles. Imanência: Uma vida..., in: Revista Educação \& Realidade, 27 (2) : 10-18, jul/dez., 2002.

DERRIDA, Jacques. Do Espírito. Campinas: Papirus, 1990.

ESPINOSA, Bento. Ética. Belo Horizonte. Autêntica Editora, 2007.

84 FONTELA, Orides. Poesia Completa, Editora Hedra, São Paulo: SP, 2015.

FOUCAULT. Michel, A hermenêutica do Sujeito: Curso dado no Collége de France (1981-1982). São Paulo: Editora WMF Martins Fontes, 2010.

HADOT, Pierre. Exercícios Espirituais e Filosofia Antiga. É Realizações Editora, São Paulo: SP, 2014.

HARRISON, Paul. The Elements of Pantheism, unterstanding the dinivity in nature and the universe. Boston : Element Books, 1999.

HARRISON, Paul."Toland: the father of modern pantheism". Pantheist History. World Pantheist Movement. Disponível em : < http://www.pantheism.net/paul/history/toland.htm> Acesso em 07 de março de 2020.

HEIDEGGER, Martin. Sein und Zeit, Tübingen, 2001.

HEIDEGGER, Martin. Wegmarken, GA 9, Frankfurt am Main, 1996.

HENRICH, Dieter (Org.). All-Einheit. Wege eines Gedankes in Ost und West. Stuttgart : KlettCotta, 1985.

HENRICH, Dieter. Pensar e ser si mesmo: preleções sobre a subjetividade. Trad. Markus A. Hediger e Lucas Machado. Petrópolis, RJ : Editora Vozes, 2018.

HERÁCLITO: Fragmentos contextualizados; tradução, apresentação e comentários Alexandre Costa. São Paulo: Odysseus Editora, 2012.

HORNÄK, Sara. Espinosa e Vermeer imanência na filosofia e na pintura. São Paulo : Paulus, 2010.

HÜBNER, Karolina. Spinoza's Parallelism Doctrine and Metaphysical Sympathy, in : In Eric Schliesser Christa Mercer (ed.), Sympathy: Oxford Philosophical Concepts, 2015, p. 146170 .

LAURAND, Valéry. La sympathie universelle : union et séparation, Revue de Métaphysique et de Morale, No. 4, Les stoïciens et le monde, p 517-535.

LEVINE, Michael, Pantheism: A Non-Theistic Concept of Deity, Psychology Press, 1994.

MYNAREK, Hubertus. Ökologische Religion. Ein neues Verständnis der Natur. Munique : Editora Wilhelm Goldmann, 1986.

PRADO JUNIOR, Bento. A Ideia de "Plano de Imanência", in: ALLIEZ, Éric. (Org.). Gilles Deleuze: uma vida filosófica. Coordenação de tradução de Ana Lúcia de Oliveria. São Paulo: Editora 34, 2000, p.307-322.

RICOEUR. Paul. Na Escola da Fenomenologia. Trad. Epharim Ferreira Alves. Petrópolis- RJ: Editora Vozes, 2009.

RICOEUR. Paul. Simpatia e respeito - Fenomenologia e ética da segunda pessoa. In: Na Escola da Fenomenologia. Trad. Epharim Ferreira Alves. Petrópolis- RJ: Editora Vozes, 2009, p. 308-332.

RORTY, R. Philosophy and the Mirror of Nature, Princeton University Press, Princeton: New Jersey, 1979.

ROLLAND, Roman. A Cintilação de Espinosa. Revista Conatus - Filosofia de Spinoza - Volume 8 - Número 16 - Dezembro 2014, p. 87-91.

SALAZAR, Heather; NICHOLLS, Roderick (Eds.). The Philosophy of Spirituality. Analytic, Continental and Multicultural Approaches to a New Field of Philosophy. Leiden ; Boston : Brill-Rodopi, 2019.

SAARINEN, Jussi. A Conceptual Analysis of the Oceanic Feeling - With a Special Note on Painterly Aesthetics. Jyväskylä University Printing House, Jyväskylä 2015

SCHELER, Max. Der Formalismus in der Ethik und die Materiale Werkethik: Neuer Versuch der Grundlegung eines Ethischen Personalismus. Halle : Editora Max Niemeyer, 1916.

SCHELER, Max.Vom Ewigen im Menschen. GW V. Bern: Francke Verlag.1968a.

SCHELER, Max.Vom Wesen der Philosophie. In: Vom Ewigen im Menschen. GW5. Bern: Francke Verlag.1968b, p.61-99. 
SCHELER, Max. Wesen und Formen der Sympathie. GW VII, Bern: Franke Verlag, 1973.

SCHELER, Max. Esencia y Formas de la Simpatía, trad. José Gaos, Buenos Aires : Editorial Losada. S.A., 1957.

SCHELER, Max.Philosophische Weltanschauung. Bern : Francke Verlag, 1954a.

SCHELER, Max.Spinoza. In: Philosophische Weltanschauung. Bern: FranckeVerlag, 1954b, p.49-61.

SCHELER, Max. Die Stellung des Menschen im Kosmos. Bonn : Bouvier Verlag,1995.

SCHELER, Max.A Posição do Homem no Cosmos. Trad.Marco Antônio Casanova. Rio

de Janeiro: Forense Universitária, 2003.

SCHELER, Max. Ordo Amoris. Trad. Arthur Morão, s.d., p.13. Disponível em : <www.lusosoha.net/textos/20120726-scheler_ordo_amoris.pdf> Acesso em: 07 de março de 2020.

STEINHART, Eric. Spiritual Naturalism. In: SALAZAR, Heather; NICHOLLS, Roderick (Eds). The Philosophy of Spirituality. Analytic, Continental and Multicultural Approaches to a New Field of Philosophy. Leiden ; Boston : Brill-Rodopi, 2019, p. 312-338.

SUSUKI, Daisetz, T. The Role of Nature in Zen Buddhism. In: Studies in Zen. London: Rider \& Company, 1955, p. 176-206.

TOLAND, John. Pantheisticon: or, the form of celebrating the Socratic-society. London, 1751. Disponível em : <https://archive.org/details/cu31924029188393/page/n17/mode/2up> Acesso em 07 de março de 2020.

\section{Notas}

1 BORNHEIM, Gerd A. Os filósofos pré-socráticos. São Paulo: Ed. Cultrix, s.d, p.28.

2 Que a palavra tem como marca a exigência de experiência concreta transparece também no frequente uso contrastante dos termos espiritualidade e religião. $\mathrm{O}$ contraponto tende a favorecer a palavra "espiritualidade" justamente porque expressaria a resistência da existência livre frente aos dogmas e ao enrijecimento institucional. É importante não perder de vista, contudo, que a dimensão comunitária e histórica da experiência religiosa é tão estrutural quanto a vivência singular. A relação com sagrado se torna comum pela sua tradução em símbolos/imagens compartilhados e pela sua celebração através de festividades e cerimônias ritualísticas. A exigência da experiência concreta não pode se restringir, portanto, à manutenção de um espaço livre para a vivência singular; precisa também ser assumida como uma tarefa de renovação ou invenção de modos comuns de vivência compartilhada que permitam uma mediação prática que torne a relação entre liberdade e instituição mais flexível e criativa.

3 FONTELA, Orides. Poesia Completa, Editora Hedra, São Paulo: SP, 2015. p.366.

4 Talvez seja possível compreender também algumas expressões das religiosidades nativas (por exemplo, de matriz africana e/ou indígena, e certas formas de xamanismo) que divinizam as forças da natureza personificando-as, como modos da perspectiva imanentista.

5 HARRISON, Paul. "Toland: the father of modern pantheism". Pantheist History. World Pantheist Movement. Disponível em : http://www.pantheism.net/paul/history/toland.htm> Acesso em 07 de março de 2020.

6 "O Pantheistikon de Toland também desbravou novos caminhos de outro modo. Foi o primeiro a conclamar por algum tipo de organização para celebrar o panteísmo. Toland sonhava com uma rede de clubes de cavalheiros [gentleman's clubs] panteístas, cujos membros se reuniriam para jantar, jogos e debate filosófico. Cada reunião começaria com uma liturgia curta, incluindo a recitação de um credo panteísta: Todas as coisas no mundo são unas [one], e uno [one] em todas as coisas. O que está todo em tudo é Deus, e Deus é eterno, não foi criado, e nunca irá morrer." HARRISON, Paul. The Elemenst of Pantheism, unterstanding the dinivity in nature and the universe. Boston : Element Books, 1999, p.31

7 Cf. ESPINOSA, Bento. Ética. Belo Horizonte. Autêntica Editora, 2010, p. 265: "Com efeito, mostramos no apêndice da primeira parte, que a natureza não age em função de um fim, pois o ente eterno e infinito que chamamos Deus ou natureza age pela mesma necessidade 
pela qual existe." (itálicos meus) Daqui em diante, utilizarei para as citações do texto da Ética a notação usual: o número romano depois de "E" indica as partes da obra; "def." indica uma definição, "ax" um axioma, "P" uma proposição, "dem” uma demonstração, "cor" um corolário e "esc" um escólio. Cf. Acerca da relação entre Espinosa e John Toland, cf. CURLEY, Erdwin. How Spinozistic Was Toland's Pantheism?, In: DILLER, Jeanine; KASHER, Asa. (Org.) Models of God and Alternative Ultimate Realities. Heidelberg: Springer, 2013. p.643-653.

8 A opção hermenêutica de classificar o pensamento de Espinosa como panenteísta padece também da falha do uso genérico do termo, sem consideração do significado oriundo da sua invenção. A pesquisa acerca da sua cunhagem por Karl Krause na obra Sistema da Filosofia, tornaria claro que o conceito pretendia preencher a função de conciliação entre mundo e Deus, resguardando, porém, para este último a transcendência frente ao primeiro. Em outras palavras, o panenteísmo, pelo menos de acordo com a proposta inaugural de Krause, não é compatível com a aplicação coerente do princípio da imanência.

9 Cf. HEIDEGGER, Martin Sein und Zeit, Tübingen, 2001, § 48, p. 244, nota.

10 Cf. HENRICH, Dieter (Org.). All-Einheit. Wege eines Gedankes in Ost und West. Stuttgart: Klett Cotta, 1985.

11 BORNHEIM, Gerd A. Os filósofos pré-socráticos. São Paulo: Ed. Cultrix, s.d, p.23.

12 CRAMER, Konrad. Gedanken über Spinozas Lehre von der All-Einheit. In: HENRICH, Dieter (Org.). All-Einheit. Wege eines Gedankes in Ost und West. Stuttgart: Klett-Cotta, 1985, p.152-153.

13 SUSUKI, Daisetz, T. The Role of Nature in Zen Buddhism. In: Studies in Zen. London: Rider \& Company, 1955, p. 183.

14 BORNHEIM, Gerd A. Os filósofos pré-socráticos. São Paulo: Ed. Cultrix, s.d, p.108.

$15 \mathrm{O}$ conceito de Einfühlung concebe a relação com o outro, segundo o princípio da subjetividade, como um acessar por meio do sentir [Fühlen] o domínio da consciência do outro, adentrando [ein] na sua esfera própria. Por isso, sua tradução por "intropatia". Utilizarei a opção "empatia", por ser uma palavra menos técnica e por dispensar o compromisso com a ideia do eu como uma esfera de reclusão ou clausura.

16 LAURAND, Valéry. La sympathie universelle : union et séparation, Revue de Métaphysique et de Morale, No. 4, Les stoïciens et le monde, p 517-535.

17 Cf. BORGES, Vitor S. Sentimento Ocêanico: um estudo da experiência religiosa a partir de Freud e Romain Rolland. Dissertação de Mestrado - Universidade Católica de Brasília, 2008, p.103. É interessante observar, que o escritor francês, recorre também à mencionada imagem no relato que faz do seu contato com o pensamento de Espinosa na sua obra Viagem Interior. Lá ele narra seu encontro com a tese da substância única com as seguintes palavras: "Eis, portanto, a resposta,(...)obstinadamente buscada, (...) ei-la radiante, a resposta ao enigma da Esfinge, que me abraça desde a infância - à antinomia opressora entre a imensidão de meu ser interior e a masmorra de meu indivíduo, que me humilha e que me sufoca! "Natureza Naturante" e "natureza naturada"... É a mesma. "Tudo o que é, é em Deus". - E eu também, eu sou em Deus! (...) Não somente meu corpo e meu espírito, meu universo, banham-se em mares sem beiras, também a Extensão, o Pensamento, cujo entorno nenhuma caravela poderá dar a volta. Porém, na insondável imensidão, ouço rumorejarem, ao infinito, outros mares, outros mares desconhecidos, Atributos inomináveis, inconcebíveis, ao infinito. E todos estão contidos no Oceano do Ser." Cf. ROLLAND, Roman. A Cintilação de Espinosa. Revista Conatus - Filosofia de Spinoza - Volume 8 - Número 16 - Dezembro 2014, p. 88.

18 SUSUKI, Daisetz, T. The Role of Nature in Zen Buddhism. In: Studies in Zen. London: Rider \& Company, 1955, p. 200. 